\section{THE INHERITANCE OF PORPHYRIA}

BY

GEOFFREY DEAN, M.D., M.R.C.P. Honorary Physician, Provincial Hospital, Port Elizabeth, South Africa

AND

H. D. BARNES, M.Sc., A.R.I.C.

Biochemical Department, South African Institute for Medical Research, Johannesburg, South Africa

The porphyrias are disorders involving profound disturbances in the metabolism of pyrrole pigments resulting at times in marked increase in the excretion of porphyrins in the urine. Familial porphyria is associated with cutaneous, psychological, and neurological symptoms. In the quiescent stage either there are no symptoms at all or there is a slightly increased sensitivity of the skin. If the skin is much exposed to the sun the sensitivity becomes more marked. Certain drugs, particularly barbiturates, precipitate an acute attack in susceptible subjects, characterized by abdominal pain, vomiting, and hysteria. Often an acute abdominal emergency is diagnosed and the patient is operated on When the acute attack has lasted a few days the patient develops a peripheral neuritis which may cause total paralysis. Many of these patients die. During an attack of acute porphyria the urine contains a great excess of. porphobilinogen and porphobilin, the latter being mainly responsible for its reddish brown colour.

\section{Historical}

It is now 75 years since the first porphyrin was discovered, by treating blood with strong sulphuric acid. The spectroscopic characteristics of the new pigment were described. At about the same time pigment with similar spectroscopic characteristics was detected in the urine of patients with some of the symptoms mentioned above. By the turn of the century a number of cases, widely scattered in Western Europe, had been described in which the urinary excretion of "haematoporphyrin" was greatly increased, and it had also been shown that a slight increase in porphyrin excretion could be detected in the urine of patients with a variety of diseases.

By 1925 the chemists had discovered that several distinct porphyrins occurred in nature, whereas haematoporphyrin prepared as described above was regarded as an artificial pigment not found in natural material. Of particular interest in connexion with clinical cases were uroporphyrin and coproporphyrin, excreted in excess in the urine and faeces of patients suffering from porphyria. It was also shown that each of these porphyrins could theoretically exist in isomeric types I, II, III, and IV, of which only I and III were found in nature. The type III porphyrins possess the same molecular structure as the porphyrin derived from haemoglobin and could not arise from, or be converted into, type I pigments without disruption of the molecule. During the same period the diseases were classified clinically into "congenital porphyria," "chronic porphyria," and " acute porphyria."

During the next 25 years increasing numbers of cases of porphyria were discovered, and improved methods for measuring and identifying the porphyrins were elaborated. At one time it was believed that the different forms of porphyria could be associated with the excretion of different kinds of porphyrin-for example, type I porphyrins in the congenital and type III in the acute forms. Whilst current methods indicate that a preponderance of the relative type excretion exists, the differentiation is not absolute, and paper chromatography has disclosed the excretion of smaller quantities of other porphyrins.

It is now recognized that porphyria is widely distributed, and as interest in, and awareness of, this condition increased, reports of cases became more frequent. Acute porphyria is common in Sweden, where Waldenström (1937) and Waldenström and Vahlquist (1944) have described close on 200 cases. It is also a common disorder in South Africa, where Barnes (1951) has already detailed the case histories and clinical findings in over 40 cases, since when many more isolated cases have been detected, and Dean (1953) has described the personal and family histories of 12 cases of acute porphyria that he has attended. The first three of these patients died, the last nine recovered. Nine further cases of acute porphyria seen since by Dean have all recovered.

A familial tendency in porphyria has been reported previously. Waldenström (1937) encountered several families in Sweden in which more than one case had occurred, and discussed the inheritance at some length. $\mathrm{He}$ pointed to three difficulties in securing complete family histories : $(a)$ affected persons were seldom aware of medical conditions in their relatives; $(b)$ the disease was little known to doctors and was usually misdiagnosed ; and (c) some susceptible members might not have developed recognizable symptoms at the time of inquiry. Waldenström thought a simple Mendelian dominance was the probable mode of inheritance. He did not find skin lesions, but this may have been owing to the fact that Sweden does not have the year-round sunshine that we have in South Africa.

The classification of porphyria into clinical forms in the past proved most obscure. The problem is the relationship of the intermediate "cutanea tarda" form to the congenital on the one hand and to the acute on the other. Watson (1952) separates the adult "cutanea tarda" and acute types, which he regards as hepatic in origin, from the congenital type starting early in childhood with staining of bone, anaemia, and a large spleen; this type he considers erythropoietic in origin. No cases in the families described here could be regarded as belonging to the rare congenital type, which would appear to be a different entity. Cockayne (1933) discussed the genetics of congenital porphyria as determined from a number of cases in Europe and Japan, abstracted from the literature, and concluded that this form is a recessive disorder due to a single gene, but there is an unexplained partial limitation to the male sex.

The purpose of this paper is to show that porphyria, as it occurs in Europeans in South Africa, is inherited as a Mendelian dominant and that it is not sex-linked. It will also be shown that in these families acute porphyria, chronic cutaneous porphyria, and "symptomless" porphyria are different manifestations of the same inherited disorder. Porphyria as seen in South Africa usually causes no symptoms in childhood.

\section{The Present Study}

The genealogies of 13 porphyric families, all of old Burgher stock and almost certainly related far back in South African history, have been traced and a number of other families await investigation. A total of 236 
members (121 male and 115 female) had clinical manifestations of porphyria. Many of them had sensitive skins that abraded easily and occasionally blistered. The sensitivity is most marked on the back of the hands and the face. The water blisters, when they occur, are small, usually about half an inch $(1.3 \mathrm{~cm}$.) in diameter, the blister breaks and leaves a sore, and eventually the hands may be scarred from many healed lesions. In some individuals the skin sensitivity is very slight and occasional. If cutaneous manifestations are present porphyrins can be detected in the urine by spectroscopic examination and by fluorescence in ultra-violet light, even though the urine may appear normal in colour. If no obvious skin sensitivity is present there may be a very little increase in the excretion of porphyrin in the urine.

Despite having a sensitive skin, most male porphyrics feel well throughout life and never develop an attack of acute porphyria. However, if they are given a thiopentone anaesthetic or take an excess of barbiturates an attack of acute porphyria may result. In women the cutaneous manifestations are usually slight, although often more apparent during pregnancy. However, in South Africa they generally know that their exposed skin is more sensitive than average and an occasional blister may have appeared. The increased sensitivity of the skin in men may be due to the fact that men are more consistently exposed to the sun and to trauma. The full explanation of the differing manifestations in the sexes is not understood; endocrine factors may be involved.

Porphyrics, particularly women, often appear to be emotionally unstable ; they complain of abdominal pains for which no cause can be found, and are often given barbiturates to relieve their symptoms, which become worse. They may persuade a surgeon to open the abdomen in the hope of finding some gynaecological or other cause for their pains. If porphyria is not diagnosed, and it seldom is, an acute attack of porphyria is very likely to occur in female porphyrics at some time during their lives. The attack is nearly always precipitated by drugs, especially barbiturates. In the acute attack the abdominal pains become severe, there is marked emotional disturbance, and over the course of a few days a generalized paralysis due to peripheral neuritis occurs. A great excess of porphyrins and porphobilinogen can then be found in the urine, which is reddish brown in colour. These attacks are associated with a marked disturbance of liver function.

Although 13 family groups have been investigated only one will be presented in this paper (see genealogical tree). We have been singularly fortunate in being able to carry out a complete survey of the urines of the living members. All the families follow a similar pattern so far as we have been able to study them.

The founder of the family described came to South Africa from Holland in 1713; his wife's family came in 1688 . His great-grandson, who was born in 1788, had four sons and one daughter, and many of the descendants of three of his sons are porphyrics. The third son, born in 1814, has had 478 descendants, 434 of whom are still alive; all of them have been traced. To-day there are members of this branch of the family in Germany, France, England, the United States, and the Rhodesias. They have all been contacted, their histories obtained, and their urine examined for porphyrin. Rimington (1952) and Wells and Rimington (1953) have emphasized the importance of estimating the faecal porphyrins. This has already been done in a number of members of this family, and a fuller account will be published in due course. In two cases a suspected parent's urine was repeatedly negative for porphyrins, although one or more descendants were undoubtedly positive; their faecal porphyrins, however, were high.

\section{Collection and Examination of Urine}

Many of the surviving members of the family still live in the Alexandria district of the Cape Province; some have migrated to other districts and more widely to the other three provinces. A few were followed to addresses over- seas. In this investigation one of us (G. D.) traced the various members, to whom letters were sent explaining the circumstances, inviting their co-operation by giving information and by submitting one or more specimens of urine. This involved a great deal of correspondence and much exasperation, but the eventual response was exceptionally good. Wherever possible information was also obtained from doctors attending the members. The urine specimens, preserved with chloroform, were sent to one of us (H.D. B.), who was not informed at the time of the family group from which the specimens came.

The urine was almost invariably turbid when received for examination and was filtered after the addition of a little "celite" (Johns Manville Co.); with a few exceptions the filtrates were quite clear, so that a deep layer up to 4-5 in. $(10-12.5 \mathrm{~cm}$.) of the paler specimens could be examined with a spectroscope against a good light. Thinner layers of more coloured specimens were examined so as to provide the best conditions for detecting any bands present in the green portion of the spectrum. About one-tenth volume of concentrated hydrochloric acid was then added to the filtered urine and spectroscopic examination repeated. Observation of two bands at about 540 and $580 \mathrm{~m} \mu$, which in the acidified specimen were replaced by a slightly broader band at $555 \mathrm{~m} \mu$, was regarded as indicating the presence of porphyrin. Examination of untreated and acidified urine in ultra-violet light for the characteristic orange or red fluorescence was always used as a check, but this method was less sensitive than spectroscopic examination.

Most of the specimens recorded as positive gave unequivocal results, but in a survey such as this it could be expected that some of the positive members were likely to be tested during a clinically quiescent stage of the disorder. With a few specimens the bands were so faint that the observer was left in some doubt of their actual presence, and repeat specimens were obtained which usually helped to clear the distinction between positive and negative findings. The requirement that the spectra of both metal complex and acid porphyrin should be seen in the appropriate specimens was a safeguard against reporting a trace of blood as porphyrin. If any doubt existed on this point it was resolved by use of the pyridine haemochromogen test. In a few specimens the pink colour of urorosein formed on acidification. These were recognized by the absorption band in the green being broader than that of acid porphyrin, and also by their negative fluorescence in ultra-violet light. Examination of the faeces for increased porphyrin excretion is of the greatest value when the diagnosis is in doubt. In young children particularly, the urine excretion was always normal, although a number must have inherited porphyria. A survey of the faecal porphyrin excretion in their cases is. being undertaken.

\section{The Inheritance}

According to Mendelian law, if a dominant characteristic is present in one partner only, half the descendants should inherit the dominant characteristic.

There are 60 porphyrics among the 125 descendants with a porphyric parent in the group shown in Table I, excluding

TABLE I.-Number of Members in Each Generation, Total Adult Children of Affected Parents, Number and Percentage of Affected Children. The Members in the Family with the Reimported Gene are Not Counted.

\begin{tabular}{|c|c|c|c|c|c|c|c|c|}
\hline \multirow{2}{*}{$\begin{array}{c}\text { Genera- } \\
\text { tion }\end{array}$} & \multirow{2}{*}{$\begin{array}{c}\text { Total } \\
\text { Members }\end{array}$} & \multicolumn{3}{|c|}{$\begin{array}{l}\text { Adult Children of } \\
\text { Affected Parent }\end{array}$} & \multicolumn{3}{|c|}{ Affected } & \multirow{2}{*}{ Affected } \\
\hline & & No. & $\mathbf{M}$ & $F$ & No. & $\mathbf{M}$ & F & \\
\hline $\begin{array}{l}\text { I } \\
\text { II } \\
\text { IV } \\
\text { V } \\
\text { VI }\end{array}$ & $\begin{array}{r}1 \\
10 \\
62 \\
173 \\
201 \\
32\end{array}$ & $\begin{array}{l}10 \\
37 \\
59 \\
19 \\
\end{array}$ & $\begin{array}{r}5 \\
16 \\
17 \\
3 \\
-\end{array}$ & $\begin{array}{r}5 \\
21 \\
42 \\
16 \\
-\end{array}$ & $\begin{array}{r}5 \\
16 \\
32 \\
7 \\
-\end{array}$ & $\begin{array}{r}3 \\
9 \\
10 \\
2 \\
\end{array}$ & $\begin{array}{r}2 \\
7 \\
22 \\
5 \\
-\end{array}$ & $\begin{array}{l}50 \\
43 \cdot 2 \\
54 \cdot 2 \\
36 \cdot 8 \\
-\end{array}$ \\
\hline Total & 479 & 125 & 41 & 84 & 60 & 24 & 36 & 48 \\
\hline
\end{tabular}

Generation $\mathrm{V}$ contains many juveniles and young adults, some of whom may yet show symptoms and raise the percentage of affected persons. All the members of generation VI are under 18 years of age. 

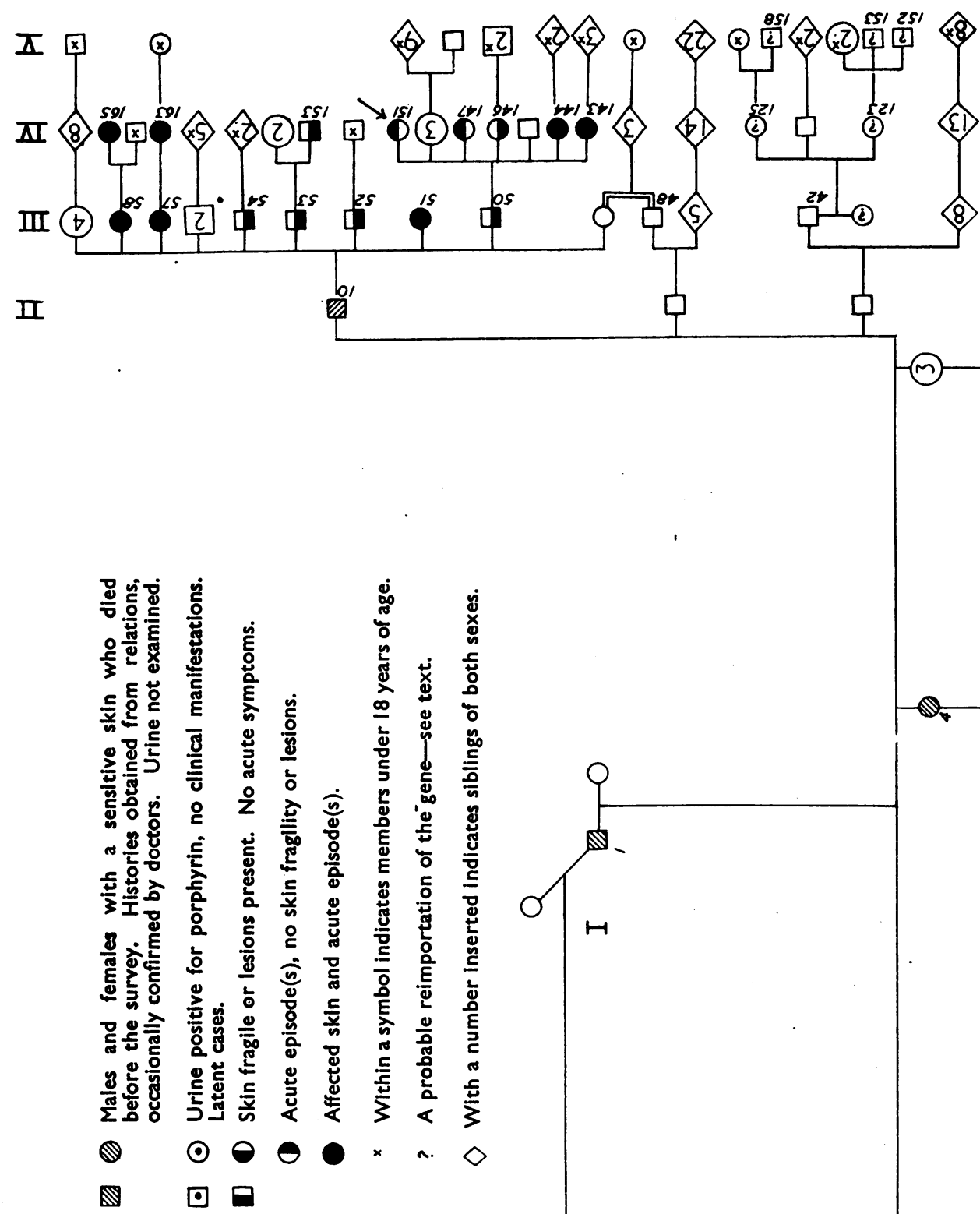

II

III

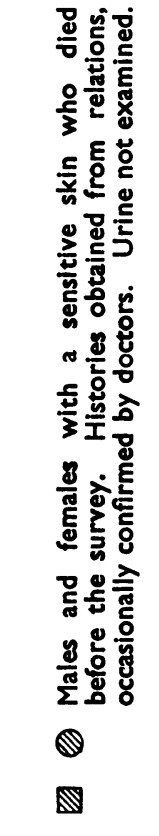
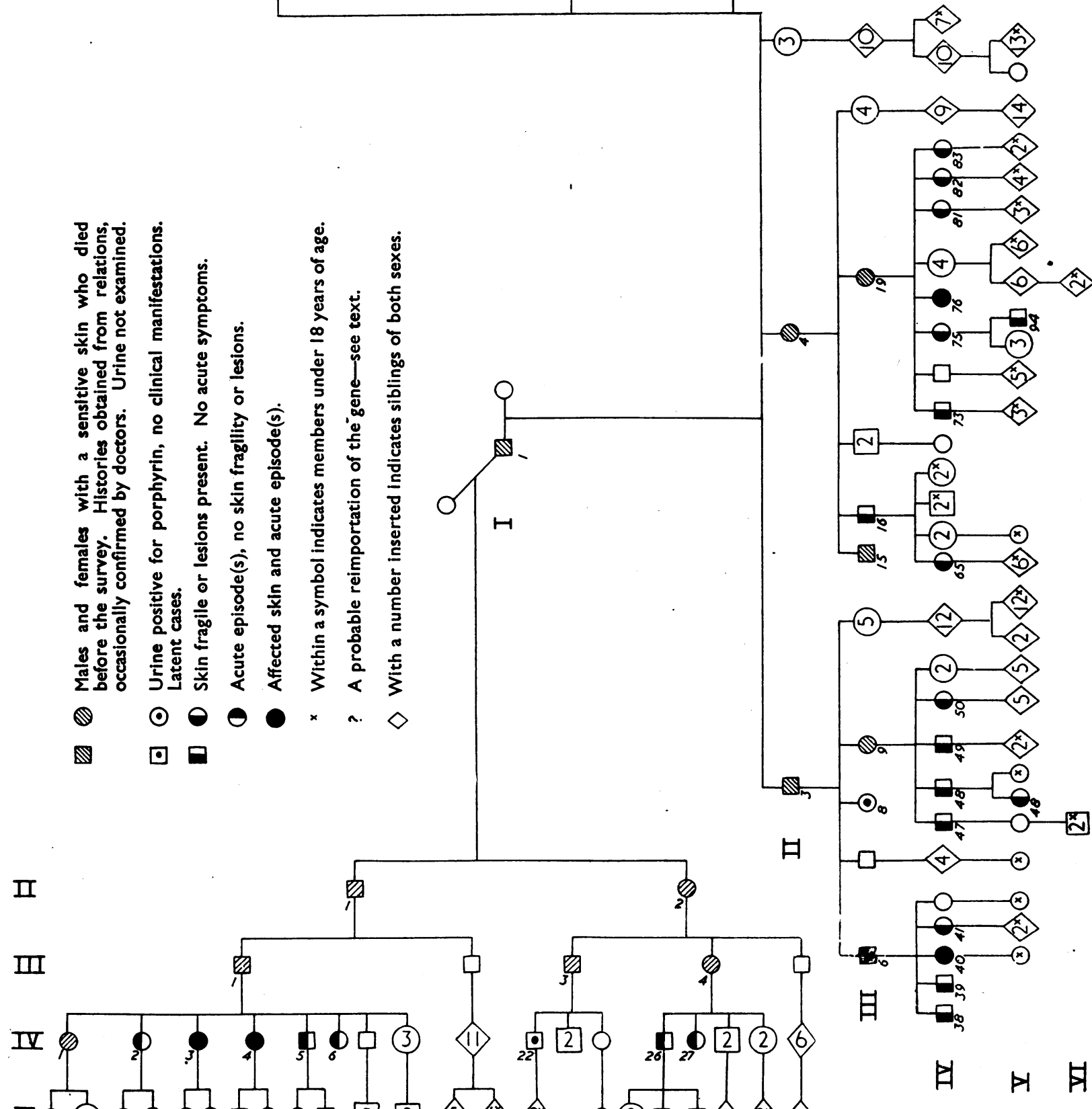
II

바 $\mathrm{H}$ 
those under the age of 18 years. In all cases only one parent is a porphyric. Five of the 10 children in the second generation are porphyrics. In the third generation there are 16 porphyrics among the 37 children with a porphyric parent. In the fourth generation there are 32 porphyrics among the 59 children with a porphyric parent. In the fifth generation there are seven known porphyrics among the 19 descendants with a porphyric parent, all young but over the age of 18 years. In this family $48 \%$ of the adults with one porphyric parent inherited porphyria; 24 out of the 41 male descendants with an affected parent, and 36 out of 84 female descendants. The corresponding figures for all 13 families together were $53.4 \%$; $51.3 \mathrm{M}$.: $48.7 \mathrm{~F}$. These conform with the theoretical requirements of a nonsex-linked Mendelian dominant type of inheritance.

The progenitor of the family group described in detail can be remembered by one remaining son-in-law, now naturally a very old man. The progenitor of this group suffered from blisters and sores on his hands much of his life. Five members (IV 123 and 125, V 152, 153, and 158) have consistently given laboratory results which, for the time being, must be regarded as equivocal. These are descendants of III 42 ; there is no evidence that he or his father (both deceased) were affected, but his wife is stated to have a sensitive skin and has shown traces of porphyrin in three specimens of urine. This group is being further studied, but is excluded from the count in Table I since, even if the affection is confirmed, it cannot be regarded as inherited from the progenitor, but has been acquired by reimportation. All the other affected members of the family have descended from the five affected children of the progenitor. This man had three brothers and one sister; many of the descendants of two of his brothers and two of his cousins are also porphyrics. In a subsequent paper it is anticipated that it will be possible to show that all Afrikaner porphyric families stem from a common forebear. In the family described there are 10 children, 62 grandchildren, 173 in the fourth generation, 201 in the fifth, and already 32 in the sixth. Of the descendants over the age of 18 years, 60 have inherited porphyria.

Only 4 of the 36 women (Table I) who inherited porphyria had severe skin sensitivity. In the remainder the skin sensitivity was very slight. Including the progenitor, 61 adults in the family have inherited porphyria (25 male and 36 female), 39 are still alive and porphyrins have been found in the urine of 35 of them; one urine is doubtful and three are negative. Among the 22 who died $(8$ male and 14 female), 1 man and 8 women have died with typical symptoms of acute porphyria.

Twenty-five men in this group have inherited porphyria, of whom 17 are still alive. Sixteen of the 17 have sensitive skins and multiple scars on their hands from previous blisters and sores. Most of them are free of symptoms except for the skin sensitivity and do not take drugs. Acute porphyria and abdominal symptoms are comparatively uncommon in male porphyrics, and most of them die eventually from some other cause. If they have been warned of the dangers of taking certain drugs, including excess alcohol, the danger of acute porphyria would appear to be slight.

Thirty-six women have inherited porphyria in this group, and 22 of them are still alive. Eight have died from acute porphyria ; a further five have had attacks of acute porphyria and have recovered. Most of the women suffer from periodic attacks of abdominal pain. A similar high proportion of acute attacks in females was found in the other families investigated. Unless the condition is correctly diagnosed in a woman, and she is warned of the dangers of taking certain drugs, it is likely that sooner or later she will have an attack of acute porphyria. Porphyrics should be given a letter showing the evidence that they suffer from the disorder and emphasizing the danger of taking certain drugs. They should be asked to show the letter to any doctor who attends them or their children.

Eleven cases of acute porphyria in the group are described in detail.

\section{Case Reports}

III 6.-A man, died aged 46, Johannesburg (1932). The history was obtained from his wife and from the hospital records. He had suffered from a sensitive skin that blistered easily since he was 20 years old. At the age of 30 , after taking sleeping tablets, he had an attack of severe abdominal pain. His abdomen was opened but no pathological condition was found. He continued to take sedatives and had recurrent attacks of abdominal pain until his final illness. During the last year of his life the pains increased in severity, and he lost $80 \mathrm{lb}$. (36.3 kg.) in weight ; he was very

TABLE II.-Summary of Positive Cases Giving Clinical Status, the Urine Findings, and the Source of the Information. The Member is Indicated by Generation (Roman Figure) and Serial Number (Arabic Numeral) Corresponding to the Chart

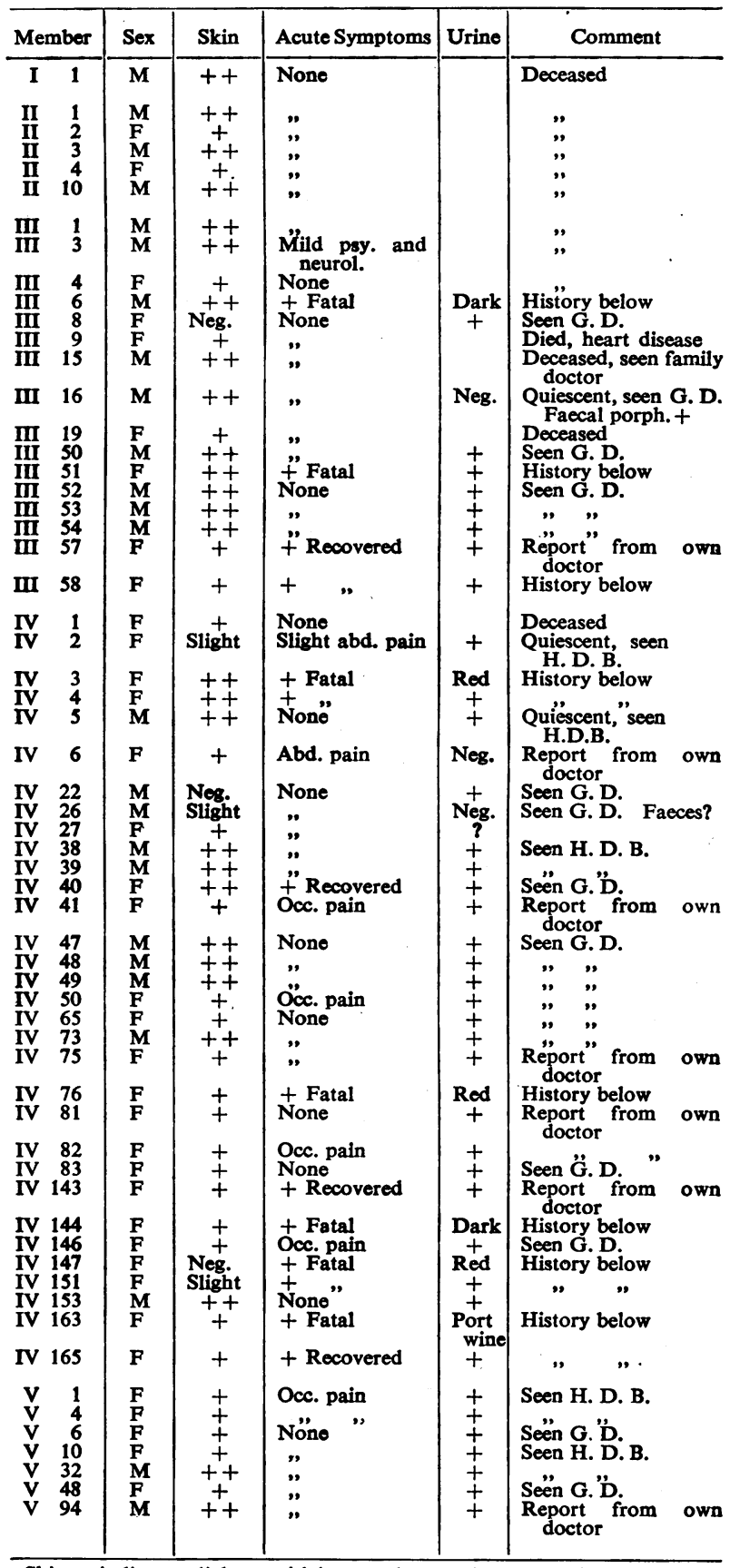

Skin + indicates slight sensitivity; perhaps only an occasional blister or exposed skin abrades when scraped with the thumb nail.

Skin ++ indicates marked sensitivity present or past. Most of the survivors have been seen personally by one of us. The histories of deceased 
constipated. Finally, he became delirious, and on admission to hospital had to be manacled. He was given repeated injections of morphine and hyoscine. His urine was of portwine colour. He was thought to have an intestinal obstruction, and a barium meal examination showed apparent delay in the small bowel. He was given a bromethol rectal injection so that a laparotomy could be performed, but his condition became so grave that the abdomen was not opened. He died a few hours later without regaining consciousness. Permission was not given for a necropsy, and death was certified as due to " chronic obstruction of ileum." Four of his five children have inherited porphyria.

III 51.-A married woman, died aged 57, Bloemfontein (1949). Information was obtained from the doctor who attended her. She had suffered periodically throughout her adult life from attacks of abdominal pain and had consulted many doctors. Her skin did not blister, but it was unduly sensitive. She had always been of a nervous and rather hysterical disposition, and had been told by most of her advisers that her symptoms were due to her nervous state. Sedatives, usually barbiturates, had been prescribed for her. A few months before her death her symptoms became more pronounced; she was very constipated and lost over $40 \mathrm{lb}$. $(18 \mathrm{~kg}$.) in weight. A month before her death she complained of marked weakness in her arms and legs and was admitted to hospital. While in hospital it was noticed that her urine was "port wine in colour." No bilharzia ova were found and only an occasional red corpuscle. The blood count, blood urea, and cerebrospinal fluid were normal. Ten days after admission to hospital her urine was tested chemically and spectroscopically for porphyrins ; the tests were positive. The urine was sent to the Institute for Medical Research in Johannesburg, where the porphyrinuria was confirmed. By this time she had become paralysed, the blood urea rose to $173 \mathrm{mg}$. per $100 \mathrm{ml}$., and she died. Permission was not granted for a necropsy.

III 58.-Morgenzon, Transvaal (1953). This woman is alive, but a detailed history is given because of its interest. She had been traced in the investigation of the family tree, but no excess of porphyrin could be detected in her urine ; however, her daughter had porphyrinuria (IV 165). She had been warned in writing that she had almost certainly inherited porphyria, and she had been informed of the type of symptoms she might suffer, in particular abdominal pains. She had been advised to warn her doctor that she could not take certain drugs, particularly barbiturates and especially a thiopentone anaesthetic. As she could not be interviewed personally, she was requested to show her doctor the letter. Despite these precautions, she allowed her doctor to give her a thiopentone anaesthetic in order to carry out an operation without informing him she was a porphyric. After the operation her condition deteriorated and she passed a dark amber urine. She gradually became paralysed. Only at this stage was a consultant, who had been called in consultation, shown the warning letter. Her urine was strongly positive when tested for porphyrins. All drugs were stopped and she was fed intravenously. She slowly recovered, and now, many months later, she is able to walk and has left hospital.

IV 3.-A woman, died aged 40, Capetown (1953). This member of the family was traced only with great difficulty. A letter was sent to the patient warning her that she might be a porphyric, describing the symptoms and explaining the dangar of taking certain drugs, particularly barbiturates. Three days later a reply was received from her daughter, who described how her mother had suffered from a sensitive skin and attacks of abdominal pains for many years; how a week before the arrival of the letter she had started to take $6 \mathrm{gr}$. $(0.4 \mathrm{~g}$.) of pentobarbitone sodium at night. The pains had increased, she became delirious and passed a reddish-brown urine. Her urine was found to contain a great excess of porphyrins. A second letter a few days later related how she had become paralysed and died. The letter warning her that she might be a porphyric had arrived a few days too late. The history was confirmed by the family doctor.
IV 4.-A woman, died aged 33 in France (1928). The husband of this woman was last heard of in 1928, at the time of his wife's death. He was thought to be somewhere in France, but his address was unknown. All that was known about him was that he originally came from Cardiff. A letter was sent to the Lord Mayor of Cardiff explaining the necessity of tracing the husband, as his children might have inherited porphyria. With the assistance of the Cardiff police he was traced to his present address in France. The husband described how his wife had suffered from a skin that blistered easily, particularly on the face and hands. She also developed small areas of pigmented skin on the face. Her ankles tended to swell, and she often suffered attacks of severe abdominal pain. After taking certain drugs at the beginning of her third pregnancy she developed severe abdominal pains, became delirious, and passed a red urine. Over the course of a few days she became paralysed and died. Death was certified as due to "black-water fever."

IV 76.-An unmarried woman, died aged 33, Port Elizabeth (1933). She had had a sensitive skin since she was 18 . She used often to suffer from attacks of abdominal pains and took a great deal of drugs, particularly for her "nerves." Following a week of severe abdominal pain she was admitted to hospital, where appendicitis was diagnosed. Bromethol was given and her appendix was removed. Even before the operation it was noticed that her urine was red in colour. After the operation she was very hysterical and was heavily sedated. Over the course of a week she became almost totally paralysed and her knee- and ankle-jerk reflexes disappeared. She died three weeks after the operation.

IV 144.-A woman, died aged 27, Grahamstown (1942). She was admitted to hospital because of severe abdominal pains, loss of weight, and marked weakness in the arms and legs. She was very hysterical and was heavily sedated with barbiturates and morphine. While in hospital it was noted that her urine was "deep amber" in colour. Within a few days her arms and legs were paralysed and a fortnight after admission to hospital she died. The family remember that she had a sensitive skin that blistered occasionally.

IV 147.-An unmarried woman, died aged 22, Port Elizabeth (1942). So far as the family remember, her skin was not noticeably sensitive. Her final illness started with abdominal pains and she became very constipated and vomited frequently. Over the course of a few weeks she lost a great deal of weight. She was given sedatives; her symptoms became so severe that she was admitted to hospital and given repeated injections of morphine for pain. At this stage she was passing a red urine, but no blood was present. A few days after admission her arms and legs were paralysed, and she died on her seventeenth day in hospital. Death was certified as due to myelitis and pyelonephritis. No further records are available.

IV 151.-A nurse, died aged 19, Uitenhage (1951). Her skin was slightly sensitive, but did not blister. She had always been of a nervous disposition and often suffered from pains in her jaw, abdomen, and limbs. She treated herself with drugs that she obtained from the hospital. Two months before her death she had all her teeth extracted because of pains. After this her symptoms became worse and she took larger doses of analgesic and sedative drugs. She complained of severe abdominal pains, vomited frequently, and was extremely constipated. As she was thought to have an intestinal obstruction a laparotomy was performed, but no obstruction was found. Thiopentone was used as an anaesthetic. After the operation she was delirious, vomited repeatedly, and had great abdominal pain. Within three days she became almost completely paralysed, her pulse was rapid, and her pupils were dilated. All the reflex jerk responses were absent. Her urine was dark amber in colour and when it was examined porphyrins and porphobilinogen were found in great excess. The urine fluoresced in ultraviolet light, and spectroscopic examination showed the porphyrin absorption bands. At this stage she was being fed intravenously. Although all drugs were stopped as soon as the diagnosis of acute porphyria was made, she died within 
a week of the operation. G. D. was called in consultation to see this case. She was the propositus of this genealogical study.

IV 163.-A married woman, died aged 24, Durban (1950). For three years before her death she had complained greatly of abdominal pains. On two occasions she was treated as a case of pyelitis because she passed a red-coloured urine. An abortion occurred in 1947, and five months before her death she gave birth to a live child. During and after pregnancy she suffered from severe attacks of abdominal pain; she frequently vomited and was very constipated. She lost a great deal of weight. She was in a very nervous state and was taking barbiturate sedatives. Six weeks before her death it was noticed that her urine was " port wine in colour." As her symptoms were becoming worse she was admitted to hospital, where a generalized paralysis of lower motor neurone type developed. She was treated with deoxycortone acetate and ascorbic acid. After a week of almost complete paralysis she died. The details about her history were obtained from ber mother and the family doctor.

IV 165.-A married woman, aged 24, acute porphyria (1954). During her 20th year she suffered from extreme nausea early in her first pregnancy, but continued to full term and gave birth to a live child. Two years later she was treated for lower abdominal pain and the cervix was cauterized. Eight months later there was an episode of epigastric pain with vomiting. Although her mother's (III 58) urine was negative when first tested for porphyrin, her urine contained an excess of porphyrin and she was warned in writing that she was a porphyric. The danger of drugs was emphasized. Seven months after this, believing herself again pregnant, she took certain drugs. She developed extreme nausea and vomiting, with abdominal pain. Constipation was marked. She became acutely ill and was fed intravenously. Her urine was reddish brown in colour, and when examined contained a great excess of porphyrin and porphobilinogen. At this stage her skin was very sensitive and abraded very easily. There was weakness of her limbs, but no true paralysis. The symptoms slowly subsided and she was discharged from hospital after three weeks.

\section{Summary}

The family tree from a large porphyric family group is presented. This group is typical of twelve others that have been investigated. In all these groups porphyria has appeared in its acute form, in its chronic cutaneous form (the "cutanea tarda" type), or as a symptomless porphyrinuria. In many cases one type changed into the other. They are different manifestations of the same inherited disorder.

It is shown that $50 \%$ of the children of a porphyric parent will inherit porphyria and that the distribution of the inheritance between the sexes is approximately equal. That is, porphyria as it occurs in South Africa is inherited as a Mendelian dominant characteristic and is not sex-linked.

If porphyria is inherited, cutaneous manifestations are more pronounced in men and are often very slight and infrequent in women. On the other hand, acute attacks are common in women. The reason for this is not fully understood. Men are more constantly exposed to the sun and to trauma; women appear more likely to be given sedative drugs or to be operated on for abdominal pain, often under a barbiturate anaesthetic. There may also be endocrine factors.

In the latent stage diagnosis may be difficult. The personal and family history is of the utmost importance, and the urine and faeces should be examined by a biochemist who is experienced in detecting porphyrins.

When a case of porphyria is diagnosed it is important to trace the genealogical tree and to investigate the other members of the family group. These investigations will usually result in the discovery of many other cases who could then be warned of the inherent danger.

We would like to express our appreciation to Mrs. C. van der Walt, who undertook the vast correspondence involved in this research; to Dr. K. van der Walt, who was responsible for the family tree; and to Dr. J. A. Fraser Roberts for advice about the final draft. Our thanks are also due to Dr. F. W. K. Grotepass, of Pretoria University, and all the other doctors in South Africa, Europe, and America who have given us their co-operation.

\section{REFERENCES}

Barnes, H. D. (1951). S. Afr. J. clin. Scl., 2, 117. Cockayne, E. A. (1933). Inherited Abnormalities of the Skin and its Appendages. Oxford Univ. Press, London.

Dean, G. (1953). British Medical Journal, 2, 1291.

Rimington, C. (1952). Second International Congress of Biochemistry. Paris.

Waldenström, J. (1937). Acta med. scand., Suppl. 82.

and Vahlquist, B. (1944). Ibid., 117, 1.

Watson, C. J. (1952). Diseases of Metabolism, 3rd ed., edited by G. G. Duncan. Philadelphia.

Wells, G. C., and Rimington, C. (1953). Brit. J. Derm., 65, 337.

\section{QUININE AMBLYOPIA}

\section{TREATMENT BY STELLATE GANGLION BLOCK}

BY

\author{
LOUIS GLICK, M.D., M.R.C.P. \\ Physician, Royal Halifax Infirmary
}

AND

JOYCE MUMFORD, M.B., B.S.

House-Physician, Royal Halifax Infirmary

Quinine, which was discovered more than 300 years ago, has proved of inestimable value in the treatment of malaria. It has played a lesser part in the treatment of muscular dystrophies. It has frequently been incorporated in proprietary and home-made antifebrile mixtures and tonic wines. Its use as an abortifacient has been reported on several occasions.

In susceptible people a dose as small as $1 \mathrm{gr}$. (65 mg.) may produce transient disturbance of vision. Permanent optic atrophy with restricted visual fields has been reported in the case of a man who drank two bottles of proprietary orange-and-quinine wine. By contrast others, especially those living in tropical climates, have taken doses of between 100 and 200 gr. (6.5 and $13 \mathrm{~g}$.) daily without obvious ill effects. There has never been a satisfactory explanation for the wide range of sensitivity to this drug. Unfortunately, the sale of this potentially dangerous substance is unrestricted and the grave risk of permanent damage, especially to the visual apparatus, is insufficiently appreciated.

\section{Case History}

A married woman aged 31 , knowing herself to be eight weeks pregnant and wishing to procure an abortion, purchased without difficulty $\frac{1}{2} \mathrm{oz}$. (15 g.) of powdered quinine sulphate at a chemist's shop. At 1 a.m. on Sunday, January 2,1955 , she dissolved the powder in a glass of port and drank the contents of the glass. Within a few minutes her vision was blurred and she experienced buzzing in her ears. She went to bed feeling very ill and in about an hour's time began to vomit. The vomiting continued repeatedly, but she eventually fell asleep. At $7 \mathrm{a} . \mathrm{m}$. the same morning she awoke to find herself completely deaf and completely blind. She remained deaf and blind throughout that day, and by the following morning the blindness was still absolute, but the hearing had improved. She was admitted to the Royal Halifax Infirmary at 4 p.m. on January 3. 